\title{
Detection of the Japanese encephalitis vector mosquito Culex tritaeniorhynchus in Australia using molecular diagnostics and morphology
}

Bryan D. Lessard ${ }^{1 *} \mathbb{0}$, Nina Kurucz ${ }^{2}$, Juanita Rodriguez ${ }^{1}$, Jane Carter ${ }^{2}$ and Christopher M. Hardy ${ }^{3}$

\begin{abstract}
Background: Culex (Culex) tritaeniorhynchus is an important vector of Japanese encephalitis virus (JEV) affecting feral pigs, native mammals and humans. The mosquito species is widely distributed throughout Southeast Asia, Africa and Europe, and thought to be absent in Australia.

Methods: In February and May, 2020 the Medical Entomology unit of the Northern Territory (NT) Top End Health Service collected $C$. tritaeniorhynchus female specimens $(n=19)$ from the Darwin and Katherine regions. Specimens were preliminarily identified morphologically as the Vishnui subgroup in subgenus Culex. Molecular identification was performed using cytochrome c oxidase subunit 1 (COI) barcoding, including sequence percentage identity using BLAST and tree-based identification using maximum likelihood analysis in the IQ-TREE software package. Once identified using COI, specimens were reanalysed for diagnostic morphological characters to inform a new taxonomic key to related species from the NT.
\end{abstract}

Results: Sequence percentage analysis of $\mathrm{COI}$ revealed that specimens from the NT shared $99.7 \%$ nucleotide identity to a haplotype of $C$. tritaeniorhynchus from Dili, Timor-Leste. The phylogenetic analysis showed that the NT specimens formed a monophyletic clade with other $C$. tritaeniorhynchus from Southeast Asia and the Middle East. We provide COl barcodes for most NT species from the Vishnui subgroup to aid future identifications, including the first genetic sequences for Culex (Culex) crinicauda and the undescribed species Culex (Culex) sp. No. 32 of Marks. Useful diagnostic morphological characters were identified and are presented in a taxonomic key to adult females to separate $C x$. tritaeniorhynchus from other members of the Vishnui subgroup from the NT.

Conclusions: We report the detection of $C x$. tritaeniorhynchus in Australia from the Darwin and Katherine regions of the NT. The vector is likely to be already established in northern Australia, given the wide geographical spread throughout the Top End of the NT. The establishment of $C$. tritaeniorhynchus in Australia is a concern to health officials as the species is an important vector of JEV and is now the sixth species from the subgenus Culex capable of vectoring JEV in Australia. We suggest that the species must now be continuously monitored during routine mosquito surveillance programmes to determine its current geographical spread and prevent the potential transmission of exotic JEV throughout Australia.

*Correspondence: bryan.d.lessard@gmail.com

1 Australian National Insect Collection, National Research Collections

Australia-CSIRO, GPO Box 1700, Canberra ACT 2601, Australia

Full list of author information is available at the end of the article permits use, sharing, adaptation, distribution and reproduction in any medium or format, as long as you give appropriate credit to the original author(s) and the source, provide a link to the Creative Commons licence, and indicate if changes were made. The images or other third party material in this article are included in the article's Creative Commons licence, unless indicated otherwise in a credit line to the material. If material is not included in the article's Creative Commons licence and your intended use is not permitted by statutory regulation or exceeds the permitted use, you will need to obtain permission directly from the copyright holder. To view a copy of this licence, visit http://creativecommons.org/licenses/by/4.0/. The Creative Commons Public Domain Dedication waiver (http://creativeco mmons.org/publicdomain/zero/1.0/) applies to the data made available in this article, unless otherwise stated in a credit line to the data. 
Keywords: Culex Vishnui subgroup, DNA barcoding, Phylogenetics, Northern Territory, Taxonomy

\section{Background}

Culex (Culex) tritaeniorhynchus Giles, 1901 is a widespread mosquito species occurring throughout Southeast (SE) Asia and extending into the Middle East, Africa and Europe [1], but is considered absent from Australia [2, 3]. The vector is a concern to health officials as the species is an important vector of Japanese Encephalitis virus (JEV; Flaviviridae: Flavivirus). This arbovirus is the leading cause of viral encephalitis in humans, with 68,000 cases reported globally each year, resulting in 20,400 deaths (25\% mortality rate) and 14,000-24,000 neurological impairments, many of which occur in children under the age of 12 years $[4,5]$. JEV also affects animals that act as reservoir hosts, including birds, cows, pigs, horses and other domestic animals [6-10], and can cause reproduction disorders and abortions in pigs [7].

Culex tritaeniorhynchus belongs to the subgenus Culex Linnaeus, 1758 and is a member of the Vishnui subgroup that comprises nine recognised species in Australasia: Culex (Culex) pseudovishnui Colless, 1957 and Culex (Culex) vishnui Theobald, 1901, both from SE Asia; Culex (Culex) omani Belkin, 1962 (Solomon Islands), Culex (Culex) incognitus Baisas, 1938 (Indonesia, Philippines), Culex (Culex) perplexus Leicester, 1908 (SE Asia, including Papua New Guinea); and the undescribed species Culex (Culex) No. 32, No. 68 and No. 92 of Marks from Australia $[2,11]$. Three species in the Vishnui subgroup are confirmed JEV vectors: $C x$. pseudovishnui, $C x$. tritaeniorhynchus and $C x$. vishnui [9]. Only two species from this subgroup are currently recognised as occurring in the Northern Territory (NT) of Australia: $C x$. No. 32 and $C x$. No. 92. The Australian species Culex (Culex) crinicauda Edwards, 1921, also occurring in the NT, was once considered as belonging to the Vishnui subgroup by Marks [11] but was later excluded from the group by subsequent taxonomists [2].

Accurate species identification of Australian mosquitoes is hindered by the lack of working taxonomists and presence of species complexes, cryptic species, rarely collected species, fragile specimens and a remarkable 170 undescribed species with unconfirmed vector status [2, 11-13]. Although more than 220 mosquito species are described from Australia [14], mosquito taxonomy did not significantly progress following the publication of the last volume of The Culicidae of the Australasian Region [15]. Regarding the Vishnui subgroup from the NT, $C x$. crinicauda, $C x$. No. 32 and $C x$. No. 92 remain difficult to morphologically differentiate. Therefore, DNA barcoding of the cytochrome $\mathrm{c}$ oxidase subunit 1 (COI) gene is often routinely used to identify troublesome species to species level $[9,16]$.

Here, we report the first confirmed records of $C x$. tritaeniorhynchus from Australia using DNA barcoding and morphology, using specimens collected from the NT. We provide DNA barcodes, high-resolution images and a taxonomic key to the adult females of Vishnui subgroup from the NT to improve species identification for future monitoring of potential JEV vectors in Australia.

\section{Methods}

\section{Specimen collection}

Between February and May 2020, 33 adult female mosquitoes were collected from the Darwin and Katherine regions in the NT, as part of the Medical Entomology (ME) Top End Health Service NT mosquito surveillance programme (Fig. 1; Additional file 1: Table S1); these were preliminarily identified as belonging to the Vishnui subgroup using the key to females of the subgenus Culex from the Australasian Region provided by Lee et al. [2]. Additional specimens included one larva collected using a 250-ml dipper and preserved in $100 \%$ ethanol from Howard Springs (Darwin region), identified as $C x$. sp. No. 32 of Marks, and an adult specimen from Timor-Leste collected in 1999, identified as Cx. tritaeniorhynchus. Two specimens of Culex (Culex) sitiens Wiedemann, 1828 and one $C x$. crinicauda were also included in the study, as these two species are the most likely to be confused with undescribed Australian Vishnui subgroup members.

$\mathrm{CO}_{2}$-baited encephalitis vector surveillance (EVS) traps were set in late afternoon and trapped adult mosquitoes were collected the following morning. The traps consist of an insulated bucket baited with $1 \mathrm{~kg}$ of dry ice, a suction fan powered by two ' $\mathrm{D}$ ' cell batteries, a 'grain of wheat' light and a rigid collection container (volume: $4 \mathrm{l}$, diameter: $220 \mathrm{~mm}$ ) fitted with a muslin sleeve and very fine wire mesh vents [17]. Adult specimens were dry mounted, vouchered and preliminarily identified using morphology. A single leg or larval segments from each specimen collected were transferred into vials containing $100 \%$ ethanol for DNA barcoding.

\section{DNA extraction and sequencing}

Total DNA was extracted from mosquito legs or larval segments using the Qiagen DNEasy Blood and Tissue Kit (Qiagen Pty Ltd., Chadstone, VIC, Australia) and eluted into $50 \mu \mathrm{l}$ TE buffer. DNA barcodes for the COI gene were obtained for each specimen using PCR 


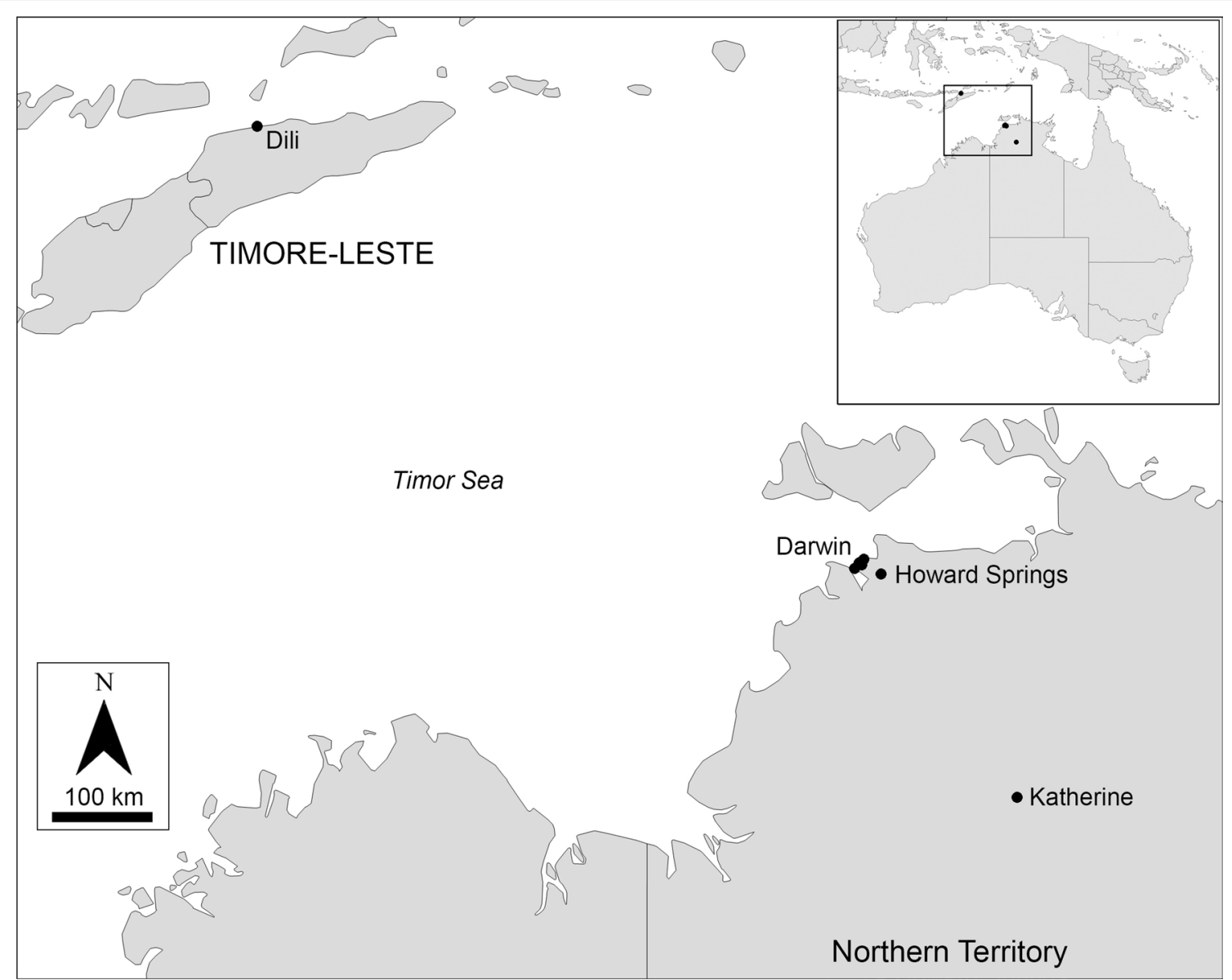

Fig. 1 Distribution of Culex (Culex) tritaeniorhynchus specimens sequenced in this study

primers LepF1 (5'-attcaaccaatcataaagatattgg- $\left.3^{\prime}\right)$ and LepR1 ( $5^{\prime}$-taaacttctggatgtccaaaaaatca-3'), and for older samples in combination with internal barcode primers MF1 (5'-gctttcccacgaataaataata-3') and MR1 (5'-cctgttccagctccattttc- $3^{\prime}$ ) [18].

DNA was amplified in a total PCR reaction volume of $50 \mu \mathrm{l}$ containing $400 \mathrm{nM}$ of each primer, $200 \mu \mathrm{M}$ dNTP, $2.5 \mathrm{mM} \mathrm{MgCl}, 1 \mu \mathrm{l}$ DNA extract ( $<1$ ng DNA), Q solution, $1 \times$ supplied buffer and $1 \mathrm{U}$ Taq (Taq PCR Core Kit; Qiagen Pty Ltd.) using the following cycling conditions: denaturation at $94{ }^{\circ} \mathrm{C}, 2 \mathrm{~min}$; then $94{ }^{\circ} \mathrm{C} / 1$ min, $45{ }^{\circ} \mathrm{C} / 1 \mathrm{~min}, 72{ }^{\circ} \mathrm{C} / 1 \mathrm{~min}$ for 5 cycles; followed by $94{ }^{\circ} \mathrm{C} / 1 \mathrm{~min}, 50{ }^{\circ} \mathrm{C} / 1 \mathrm{~min}, 72{ }^{\circ} \mathrm{C} / 1 \mathrm{~min}$ for 35 cycles; with a final incubation step at $72{ }^{\circ} \mathrm{C}$ for $10 \mathrm{~min}$. The presence of PCR products was confirmed by agarose gel electrophoresis before purification and elution into $32 \mu \mathrm{l}$ EB buffer using the QIAquick PCR Purification Kit (Qiagen Pty Ltd.). PCR products were sent for Sanger sequencing using an ABI 3730xl system by Macrogen Inc. (Seoul, South Korea).

\section{Sequence divergence and phylogenetic analysis}

The COI sequences for a total of 38 Culex (Culex) species were obtained (GenBank Accession Numbers MW809416-MW809453; Additional file 1: Table S1) and aligned in MEGA X [19]. Additional sequences were sourced from GenBank to cover: (i) a wide geographical range of $C x$. tritaeniorhynchus (i.e. specimens collected from China, India, Japan, Pakistan, United Arab Emirates and Vietnam); (ii) related species from the Vishnui subgroup (Cx. pseudovishnui and $C x$. vishnui); (iii) a range of Culex (Culex) species: Culex (Culex) annulirostris Skuse, 1889, Culex (Culex) australicus Dobrotworsky \& Drummond, 1953, Cx. crinicauda, Culex (Culex) gelidus Theobald, 1901, Culex (Culex) globocoxitus Dobrotworsky, 1953, Culex (Culex) molestus Forsskål, 1775, Culex (Culex) palpalis Taylor, 1912, Cx. sitiens, Culex (Culex) quinquefasciatus Say, 1823, all occurring in Australia, and the exotic species Culex (Culex) annulioris Theobald, 1901, Culex (Culex) mimeticus Noè, 1899, Culex (Culex) orientalis Edwards, 1921, Culex (Culex) pervigilans Bergroth, 
1889 and Culex (Culex) vagans Wiedemann, 1828); (iv) widespread species that also occur in Australia that have been reported in previous phylogenetic analyses as recovering within the Culex (Culex) clade: Culex (Oculeomyia) bitaeniorhynchus Giles, 1901 and Lutzia (Metalutzia) halifaxi (Theobald, 1903) [20, 21]; (v) and the chosen outgroup, Culex (Neoculex) fergusoni (Taylor, 1914).

Phylogenetic analysis was performed on the CSIRO Pearcey high-performance computing cluster using IQ-TREE version 2.0.6 [22], with 1000 ultrafast bootstrap replicates [23] and the best partitioning scheme [24] implementing a separate partition model for each codon position as follows: position 3 , TN $\{40.5634,16.4236\}+F \quad\{0.462515,0.0346759,0$. $0197159,0.483093\}+$ G4 $\{0.863244\} ;$ position $1, \mathrm{TNe}$ $\{4.35032,70.0487\}+F Q+G 4 \quad\{0.147506\}$, and position 2, F81. Nodes with ultrabootstrap support of < $50 \%$ were collapsed in the final tree using Interactive Tree of Life version 6.1 [25]. In cases where a species had multiple specimens sharing identical haplotypes, a representative specimen was chosen to include in the phylogenetic analysis, with the clade number annotated on the phylogeny (as specified in Additional file 1: Table S1). Percentage identity of the DNA barcodes was calculated using the blastn suite in BLAST (basic local alignment search tool) [26] in GenBank (https://blast. ncbi.nlm.nih.gov/Blast.cgi) for the Australian specimens, focussing on $C x$. tritaeniorhynchus to provide insights into the potential origin of the vector.

\section{Morphological identification}

After a leg was removed for DNA extraction, pinned adult specimens were examined under a Zeiss dissecting microscope (Carl Zeiss AG, Jena, Germany) and identified using the key to adult females of Australasian Culex (Culex) provided by Marks in Lee et al. [2]. Diagnostic morphological features were identified after comparing recently collected specimens to reference material held in the CSIRO Australian National Insect Collection, Canberra, and Elizabeth 'Pat' Marks mosquito collection held at the Queensland Museum, Brisbane. A taxonomic key was prepared to separate adult females of $C x$. tritaeniorhynchus from morphologically similar species from the NT.

Photographs were taken on a BK Imaging-PLUS Lab System (Visionary Digital, Hollywood, CA, USA) using a Canon $65 \mathrm{~mm}$ lens (Canon Inc., Tokyo, Japan) stacked in Zerene Stacker v 1.0 software and processed in Adobe Photoshop CS6 (Adobe Inc., San Jose, CA, USA) to obtain a fully-sharpened image. Morphological terminology follows Harbach and Knight $[27,28]$.

\section{Results}

\section{Molecular diagnostics}

Standard length (658 bp) COI DNA barcodes were obtained for mosquitoes preliminarily identified using morphology as belonging to the Vishnui subgroup. These were collected between 1999 and 2020 from the NT $(n=34)$ and Timor-Leste $(n=1)$ (Additional file 1: Table S1). More than half $(n=19)$ of the Vishnui subgroup specimens sequenced from the NT were identified by COI barcoding as Cx. tritaeniorhynchus, sharing 98.298.8\% nucleotide identity with records from Japan and/or Pakistan using BLAST in GenBank. Four different haplotypes were observed for the Australian $C x$. tritaeniorhynchus specimens: haplotype T1 ( $n=7$ : Katherine, Leanyer (Darwin urban), RAAF Base Darwin); haplotype T2 ( $n=4$ : Howard Springs (Darwin region), Leanyer, RAAF Base Darwin); haplotype T3 $(n=7$ : Darwin International Airport, Howard Springs, Karama (Darwin urban), Leanyer, RAAF Base Darwin), and; haplotype T4 $(n=1$ : Howard Springs) (Additional file 1: Table S1; Fig. 2).

The Cx. tritaeniorhynchus specimens from the NT were most similar (99.7\% nucleotide identity) to a specimen sequenced from Dili, Timor-Leste, collected in December 1999. One specimen identified as Cx. crinicauda was collected from the McArthur River Mine, located $900 \mathrm{~km}$ south-east of Darwin, and shared 95.1\% nucleotide identity to a record of Culex (Culex) orientalis Edwards, 1921 from Japan, and $94.4 \%$ to a record of Culex (Culex) mimeticus Noè, 1899 also from Japan. The remaining 14 specimens collected from the Darwin region (subsequently confirmed morphologically as Culex sp. No. 32 of Marks), shared 96.0-96.4\% nucleotide identity with records of $C x$. pseudovishnui from Japan, and comprised three haplotypes: haplotype M1 $(n=12$ : Holtze [Darwin region], Karama, Leanyer, Lee Point [Darwin urban], Marrara [Darwin urban], Tiwi [Darwin urban], Winnellie [Darwin urban]); haplotype M2 ( $n=1$ : Howard Springs); and haplotype M3 ( $n=1$ : Leanyer) (Additional file 1: Table S1; Fig. 2).

Tree-based identification using maximum likelihood estimation revealed that $C x$. tritaeniorhynchus recovered as a moderately supported monophyletic clade (ultrafast bootstrap support $=81 \%$; Fig. 2). Sequence variation did not give any indication of geographic structure, as multiple specimens from each country recovered as paraphyletic. For instance, specimens from Australia were not monophyletic, but instead grouped within the larger $C x$. tritaeniorhynchus clade of Darwin $+([$ Darwin + Timor $]$ + Darwin $+[$ Darwin $+\{$ Japan $+($ China + Japan $)\}])$. The Vishnui subgroup recovered as a strongly supported monophyletic clade (ultrabootstrap support $=93 \%$ ), grouping as $C x$. tritaeniorhynchus $+(C x$. vishnui $+[C x$. pseudovishnui + Culex sp. No. 32 of Marks]) (Fig. 2). 


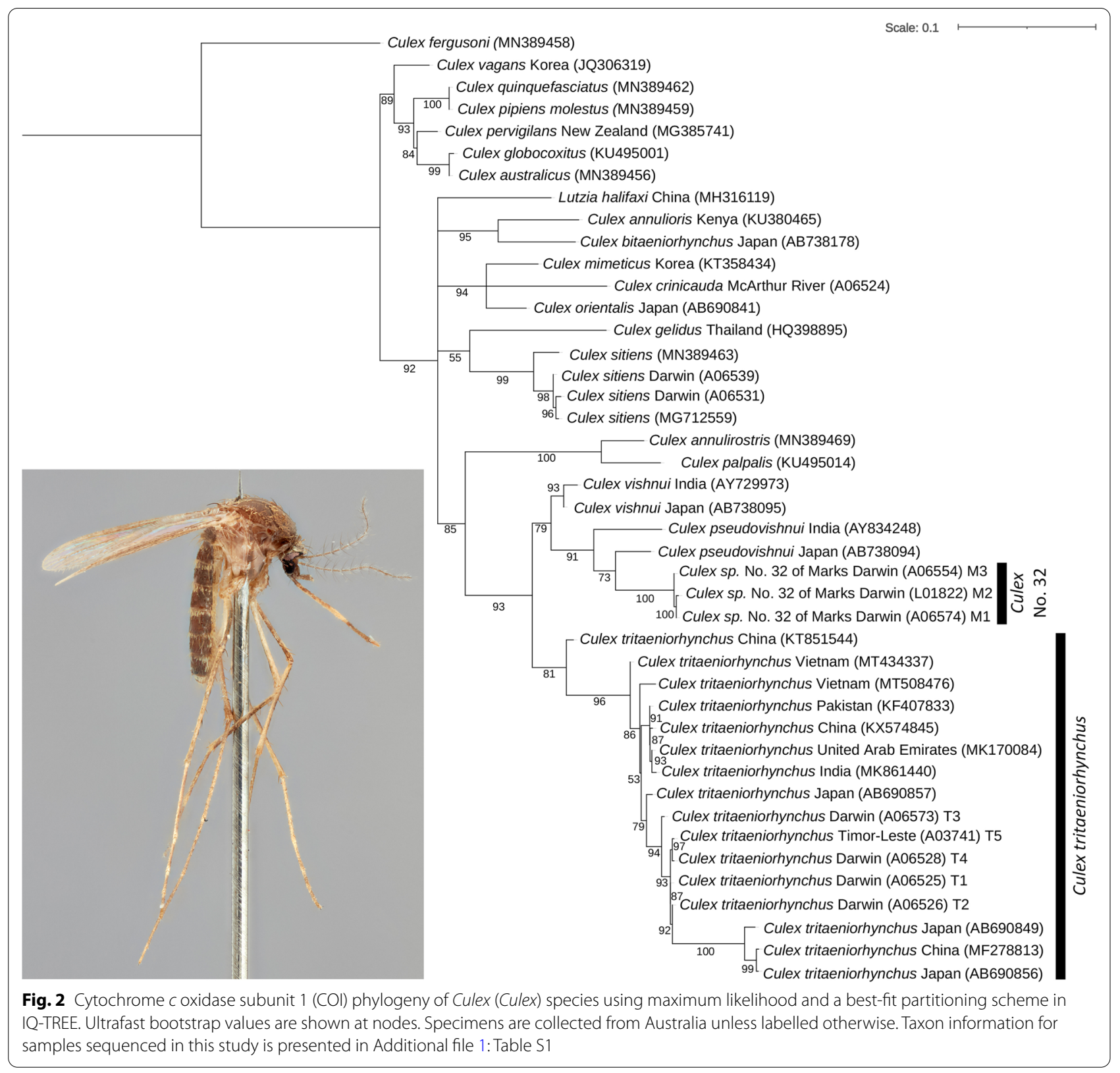

However, Cx. crinicauda was excluded from the Vishnui subgroup, which instead recovered as a strongly supported polytomic clade (ultrabootstrap support $=94 \%$ ) with $C x$. orientalis and $C x$. mimeticus. The undescribed species Culex sp. No. 32 of Marks formed a strongly supported monophyletic group (ultrabootstrap support $=100 \%$ ), sister to Cx. pseudovishnui (Fig. 2).

\section{Morphological identification}

Once species identify was confirmed using the COI gene, reference specimens were re-examined for informative morphological characters that could be used to diagnose species. Regarding the Australian Culex (Culex) fauna, Cx. tritaeniorhynchus is likely to be confused with the undescribed species Culex No. 32 of Marks, sharing the overall brown coloration, as well as narrow, pale banded scaling on the proboscis, abdomen and, to a lesser extent, the legs. The two species, however, can be separated based on the morphological characters provided in the following key to adult females of the Vishnui subgroup and morphologically similar Cx. crinicauda from the NT: 
1. Occiput with erect forked scales predominantly white, sharply contrasting with cuticle; scutum with prominent, dense whitish scaling, sharply contrasting with cuticle... crinicauda Edwards, 1921

- Occiput with erect forked scales predominantly brown, more uniform with cuticle; scutum with predominantly pale brown scaling, if white scaling is present, it is usually dispersed, never forming dense patches... 2

2. Proboscis with very narrow pale band, approximately 0.1 times length of proboscis, not sharply contrasting remaining proboscis; pale-brown species... sp. No. 92 of Marks (1982)

- Proboscis with well-defined pale band, at least 0.2 times length of proboscis, sharply contrasting remaining proboscis; darker species... 3

3. Legs pale brown, posterior mid and hind femora almost entirely pale yellowish to white, anterior surface of mid tibiae almost uniform brown, without pale line (Fig. 3b, h); vertex with erect forked scales predominantly dark (Fig. 3e); scutum with uniform dull brown scaling, without obvious patches of whitish scales (Fig. 3e, f); pleura with predominantly bare scaling on proepisternum, occasionally with only a few whitish scales, reduced on upper and lower mesokatepisternum, upper mesanepimeron, and anterior surface of forecoxa (Fig. 3e)... tritaeniorhynchus Giles, 1901

- Legs dark brown with strongly contrasting pale banding, posterior mid and hind femora dark brown on apical third, strongly contrasting pale yellowish white basal two thirds, anterior surface of mid tibiae with a longitudinal pale scale patch strongly contrasting dark scales (Fig. 4b, h); vertex with erect forked scales pale medially, becoming dark laterally (Fig. 4e); scutum scaling pale brown, with contrasting whitish scaling present at dorsocentral areas, scutal angle, prescutellar and supra-alar areas (Fig. 4e, f); pleura with relatively dense scaling, broad whitish on proepisternum, upper and lower mesokatepisternum, upper mesanepimeron, and anterior surface of forecoxa (Fig. 4e)... sp. No. 32 of Marks (1982).

\section{Discussion}

Culex tritaeniorhynchus appears to be established in the NT, with confirmed collection records from the Darwin region, extending $270 \mathrm{~km}$ further SE to Katherine (Fig. 1). Tree-based identification using a 658-bp COI barcoding region demonstrated moderate support for the monophyly of $C x$. tritaeniorhynchus collected throughout the world, including Australia, China, India, Japan, Pakistan, Timor-Leste, United Arab Emirates and Vietnam (Fig. 2). Sequence divergence results indicate that the Australian $C x$. tritaeniorhynchus population most likely originated from Timor-Leste, sharing 99.7\% nucleotide similarity. Geographically, Timor-Leste is separated by approximately $620 \mathrm{~km}$ from Australia by the Timor Sea and is the closest known population of $C x$. tritaeniorhynchus to the Darwin region.

While the introduction pathways are unconfirmed, it is plausible that Cx. tritaeniorhynchus may have travelled to Australia from Timor-Leste via windblown adult mosquitoes, given the relatively short distance of $465 \mathrm{~km}$ between Timor-Leste and Melville Island near Darwin, and that $C x$. tritaeniorhynchus has been previously recorded as flying $200-500 \mathrm{~km}$ over sea waters in the Northwest Pacific [29]. Alternatively, the vector may have arrived in Australia with adults being transported on board aircraft, or most likely as larvae and/or pupae inadvertently stowed on cargo ships. In one study documenting the number of mosquitoes detected on ships arriving in China from abroad, $C x$. tritaeniorhynchus was one of the most common mosquito species recorded [10, 30]. Moreover, transportation via shipping vessels has been identified as the main point of entry for the introductions and subsequent establishment of other Culex (Culex) species into Australia, including Cx. molestus (by US forces during the Second World War) and $C x$. quinquefasciatus (by European colonists, US whalers or international trade) [10,31].

The Australian members of subgenus Culex remain difficult to identify using morphology alone, with accurate species identification hindered by the presence of undescribed [11] or potential cryptic species [13]. We demonstrate that DNA barcoding is useful for identifying members of the Vishnui subgroup from the NT and present the first genetic sequences to be provided for $C x$. crinicauda and Culex sp. No. 32 of Marks. The Vishnui subgroup recovered as a strongly supported monophyletic group in the COI phylogeny (Fig. 2), excluding $C x$. crinicauda which instead formed a clade with $C x$. orientalis and $C x$. mimeticus. Although $C x$. crinicauda was previously proposed to be part of the subgroup [11], our results support the decision of Lee et al. [2] to exclude it from the Vishnui subgroup. The monophyly of the 


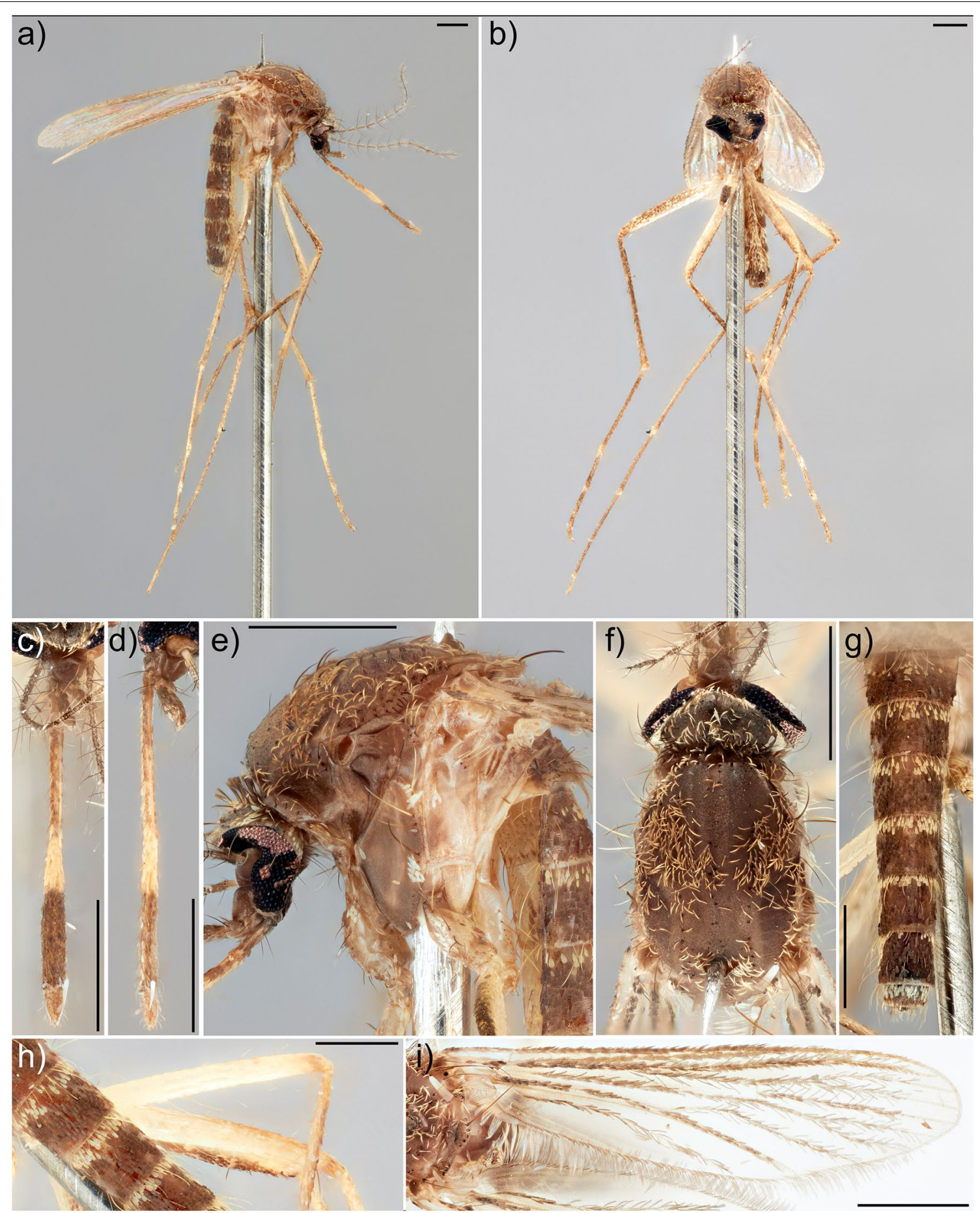

Fig. 3 Culex (Culex) tritaeniorhynchus, female (NT Health A06525). a Body, lateral; b body, frontal; c proboscis, dorsal; d proboscis, lateral; e thorax, lateral; $\mathbf{f}$ scutum; $\mathbf{g}$ abdomen, dorsal; $\mathbf{h}$ posterior of legs, hind (top) and mid (bottom); i wing, dorsal. Scale bars: $0.5 \mathrm{~mm}$. Collection label data: "NM08542 A06525/12 $22^{\prime} 15^{\prime \prime S} 131^{\circ} 1^{\prime} 45^{\prime \prime}$ E/AUS., NT, Litchfield Shire/Stow Road, behind Manigur/Coll: 27-Feb-2020/Coll: A Roberts/Coll type: CO2" 

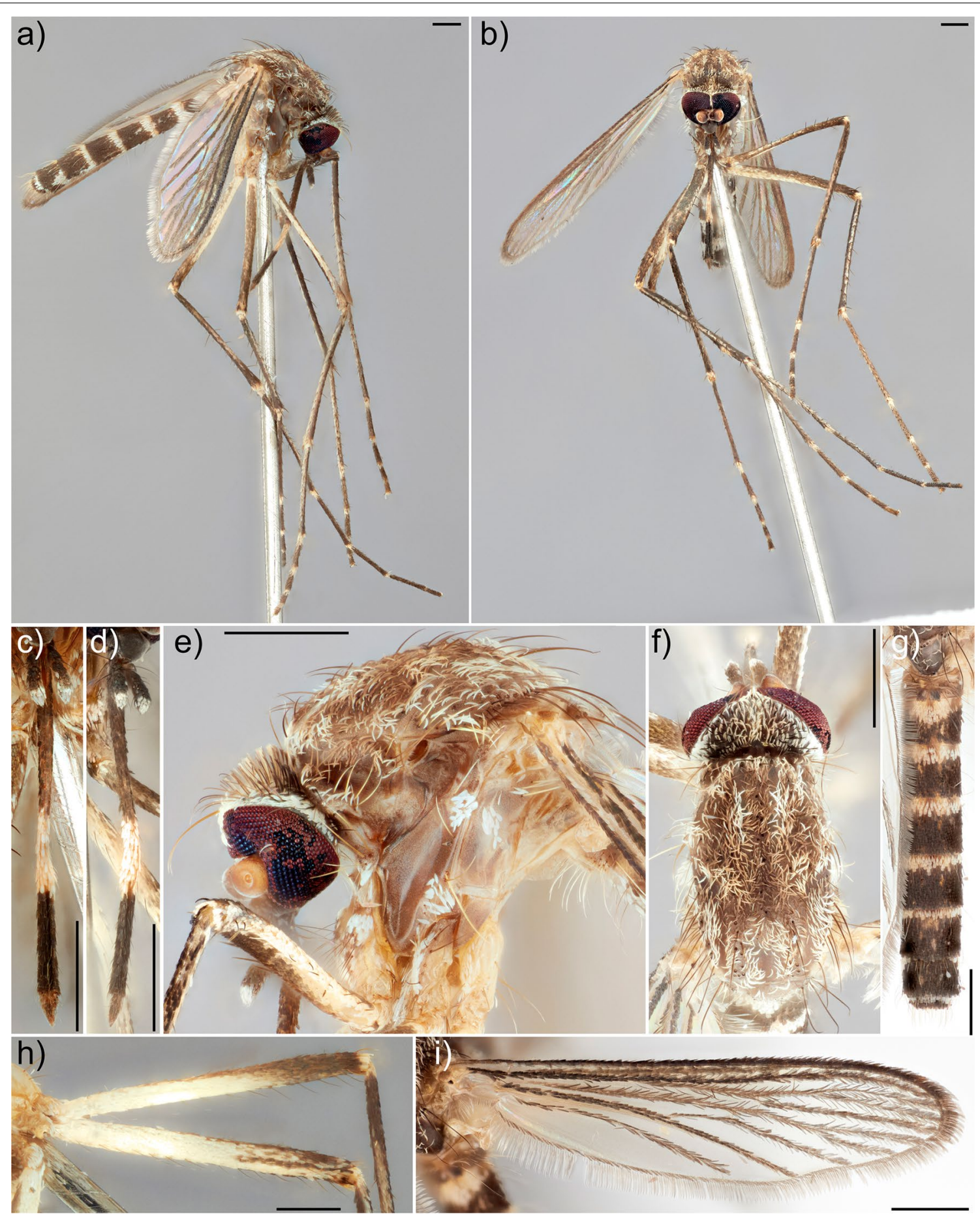

Fig. 4 Culex (Culex) sp. No. 32 of Marks, female (NT Health A06575). a Body, lateral; b body, frontal; c proboscis, dorsal; d proboscis, lateral; e thorax, lateral; $\mathbf{f}$ scutum; $\mathbf{g}$ abdomen, dorsal; $\mathbf{h}$ posterior of legs, hind (top) and mid (bottom); $\mathbf{i}$ wing, dorsal. Scale bars: 0.5 mm. Collection label data: "NM08559 A06575/12²4'26"S 13054'44"E/AUS., NT, Darwin/DM08 Marrara Round Swa/Coll: 14-May-2020/Coll: T Okazaki/Coll type: CO2" 
Vishnui subgroup is also supported by the COI phylogeny presented by Karthika et al. [9]. The undescribed species Culex sp. No. 32 of Marks also formed a strongly supported monophyletic group in our phylogenetic analysis, sister to Cx. pseudovishnui, demonstrating that it is in fact a valid species in need of formal taxonomic description. A modern taxonomic revision combining morphology and molecular data is warranted for the Australian mosquitoes to improve species identification and the detection of future incursions of invasive species.

Culex tritaeniorhynchus occurs in sympatry with other species from the Vishnui subgroup from the NT. It is most likely to be confused morphologically with the undescribed species Culex sp. No. 32 of Marks (Fig. 4). Nevertheless, both species can be reliably identified using the COI gene, as each species formed distinct monophyletic clades in the molecular phylogeny (Fig. 2). Adult females of $C x$. tritaeniorhynchus can be distinguished from all other species of the Vishnui subgroup from the NT by a combination of the following traits: vertex with erect forked scales mostly dark; scutum with uniform dull brown scaling; legs with posterior surface of mid and hind femora almost entirely pale yellowish to white, anterior surface of mid tibiae almost uniform brown and without a longitudinal pale scale patch; and pleura with proepisternum without scaling, and reduced scaling on upper and lower mesokatepisternum, upper mesanepimeron and anterior surface of forecoxa (Fig. 3).

The vector may have been first introduced into Australia several decades ago, since $C x$. tritaeniorhynchus larvae were reportedly collected during larval surveys from Darwin and the Kimberley Research Station in the state of Western Australia in the 1950s [32, 33]. However, the larvae were not illustrated and the whereabouts of the original specimens are unknown. Moreover, larvae of $C x$. tritaeniorhynchus and $C x$. sp. No. 32 of Marks are very similar morphologically, sharing similar pecten spines, comb scaling and branching setae of the head [34, 35]. Therefore, it is possible that these early larval records of $C x$. tritaeniorhynchus were misidentifications of $C x$. sp. No. 32 of Marks that was unknown at the time.

Culex tritaeniorhynchus is the most recent exotic Culex (Culex) species to be detected in Australia in more than 20 years. Culex gelidus (distributed in India and Southeast Asia), also a known JEV vector, was first detected in Australia in 1999 and was introduced via aircraft in northern Queensland, before spreading further and becoming established in the NT and northern Western Australia [36-38]. Six JEV vectors from the Culex (Culex) are now known to occur in Australia: Cx. annulirostris, Cx. gelidus, Cx. quinquefasciatus, $C x$. sitiens, $C x$. tritaeniorhynchus and Culex (Culex) whitmorei (Giles, 1904) [39].

Eradication programmes of mosquito vectors are cost prohibitive and further complicated by widespread species [40, 41]. However, following the detection of $C x$. tritaeniorhynchus in the Darwin and Katherine regions (Fig. 1), it appears that the species is already widely established, therefore elimination is most likely unfeasible. The full distribution of Australian breeding sites of $C x$. tritaeniorhynchus is unknown, although breeding habitats appear to be broad overseas, including temporary and semi-permanent shaded ground pools $[1,10]$, which are common in the NT. Moreover, vertical transmission of JEV has been noted in $\mathrm{F}_{1}$ progeny of $C x$. tritaeniorhynchus, as has the ability of females to overwinter and estivate in colder months [10, 42, 43], both of which enhance the threat of the JEV vector becoming established and expanding into suitable environments [1]. Increased larval and adult surveys in the NT and northern Western Australia are needed to confirm the current geographical spread and continued presence of the species. Historically collected specimens held in mosquito surveillance and entomological collections may be useful in tracing the origins and first detection of the species in Australia, especially given the recent advances of sequencing DNA from museum mosquito specimens [44].

An estimated 2.3-6.3 million feral pigs occur in Australia [45], with 6.1 pigs $\mathrm{km}^{-2}$ estimated from the Mary River region in the NT alone [46]. As pigs are known amplifier hosts for JEV [37], the establishment of $C x$. tritaeniorhynchus in Australia may be considered a public health concern due to the abundance of feral pigs occurring across northern Australia, which may increase infection rates and potentially lead to emerging JEV outbreaks [3,37].

Recent vector competence testing has shown that possums and the black flying fox Pteropus alecto are potential amplifying hosts for JEV in Australia, compared to those considered to be poor hosts, such as the eastern grey kangaroos, agile wallabies and tammar wallabies [22, 47-49]. Van den Hurk et al. [3] suggested that flying foxes could play a prominent role in the transmission of JEV into northern Australia, since thousands of individuals migrate to Australia from Torres Strait and New Guinea where the virus is more prevalent. Future vector competency testing should be conducted to assess whether JEV could be spread by other Australian members of the Vishnui subgroup, including Culex sp. No. 32 of Marks.

Although JEV is relatively rare and yet to be established in Australia [3, 12], northern Australia is a JEV risk area [39]. The first outbreak of the arbovirus was 
last detected in 1995 in humans and pigs from the Torres Strait and Cape York peninsula, northern Queensland, most likely introduced by migratory birds or windblown mosquitos from New Guinea and amplified by the native JEV vector mosquito $C x$. annulirostris [6, 50]. Therefore, the additional JEV vector $C x$. tritaeniorhynchus must now be continuously monitored for to prevent the potential health risk of transmitting this exotic disease in Australia.

\section{Conclusions}

The JEV vector $C x$. tritaeniorhynchus is detected for the first time in Australia from the Darwin and Katherine regions in the NT. Molecular analysis of the COI gene confirmed the identify of specimens collected from the NT as belonging to Cx. tritaeniorhynchus, most likely originating from Timor-Leste. Accurate species identification of exotic species with known affinities for disease transmission is essential for improving the monitoring of high-risk mosquito species to better predict and manage emerging mosquito-borne diseases in Australia.

\section{Abbreviations}

BLAST: Basic local alignment search tool; COI: Cytochrome c oxidase subunit 1; CSIRO: Commonwealth Scientific and Industrial Research Organisation; JEV: Japanese Encephalitis virus; ME: Medical Entomology Top End Health Service NT mosquito surveillance programme; NT: Northern Territory.

\section{Supplementary Information}

The online version contains supplementary material available at https://doi. org/10.1186/s13071-021-04911-2.

Additional file 1: Table S1. Australian Culex (Culex) spp. mosquitoes sequenced in this study, focusing on the Vishnui subgroup.

\section{Acknowledgements}

The authors would like to thank Peter Whelan (Biting Insect Technical Extension Services) for collecting (X. tritaeniorhynchus from Timor-Leste, Christine Lambkin, Karin Koch and Susan Wright (Queensland Museum) for providing access to and loaning of specimens from the Elizabeth 'Pat' Marks mosquito reference collection, Cameron Webb (NSW Health Pathology) for providing specimens of $C$ x. sp. No. 32 of Marks from NSW for comparison, David Yeates (ANIC) for offering advice throughout the project and to all Medical Entomology staff involved in the collection and processing of specimens.

\section{Authors' contributions}

$\mathrm{BL}, \mathrm{NK}, \mathrm{JC}$ and $\mathrm{CH}$ contributed to the overall study design. NK and JC collected and preliminary identified specimens in the field. $\mathrm{CH}$ extracted and sequenced DNA from specimens. JR and BL analysed the molecular data. BL photographed specimens, identified diagnostic morphological characters and wrote the taxonomic key. BL, NK and CH drafted and revised the manuscript. All authors read and approved the final manuscript.

\section{Funding}

Funding was provided by the Australian and NT Governments, including the Australian Biological Resources Study (ABRS) National Taxonomy Research Grant Program project "Rebooting mosquito biosystematics in Australia: integrative taxonomy of the subgenus Culex (Diptera: Culicidae)" (RG 18-19).

\section{Declarations}

Ethics approval and consent to participate

Not applicable.

\section{Consent for publication}

Not applicable.

\section{Availability of data and materials}

Sequence data that support the findings of this study have been deposited in GenBank with the accession codes provided in Additional file 1: Table S1.

\section{Competing interests}

The authors declare that they have no competing interests.

\section{Author details}

${ }^{1}$ Australian National Insect Collection, National Research Collections AustraliaCSIRO, GPO Box 1700, Canberra ACT 2601, Australia. ${ }^{2}$ Medical Entomology, NT Health-Royal Darwin Hospital, Top End Health Service, GPO Box 41326, Casuarina, NT 0810, Australia. ${ }^{3}$ CSIRO Land and Water, GPO Box 1700, Canberra ACT 2601, Australia.

Received: 13 May 2021 Accepted: 31 July 2021

Published online: 18 August 2021

\section{References}

1. Longbottom J, Browne AJ, Pigott DM, Sinka ME, Golding N, Hay SI, et al. Mapping the spatial distribution of the Japanese encephalitis vector, Culex tritaeniorhynchus Giles 1901 (Diptera: Culicidae) within areas of Japanese encephalitis risk. Parasites Vectors. 2017;10:148.

2. Lee DJ, Hicks MM, Debenham ML, Griffiths M, Marks EN, Bryan JH, et al. The Culicidae of the Australian region, vol. 7. Canberra: Australian Government Publishing Service; 1988.

3. van den Hurk AF, Pyke AT, Mackenzie JS, Hall-Mendelin S, Ritchie SA. Japanese encephalitis virus in Australia: from known known to known unknown. Trop Med Infect Dis. 2019;4:38.

4. Centers for Disease Control and Prevention. Japanese encephalitis surveillance and immunization-Asia and the Western Pacific. Morb Mortal Wkly Rep. 2013;62:658.

5. Bosco-Lauth A, Mason G, Bowen R. Pathogenesis of Japanese encephalitis virus infection in a golden hamster model and evaluation of flavivirus cross-protective immunity. Am J Trop Med Hyg. 2011;84:727-32.

6. Halstead SB, Jacobson J. Japanese encephalitis. Adv Virus Res. 2003;61:103-38.

7. Himani D, Kumar HC, Bhilegaonkar KN, Kumar A. Japanese encephalitis: a veterinary perspective. J Foodborne Zoon Dis. 2014;2:59-67.

8. Luo QC, Hao YJ, Meng F, Li TJ, Ding YR, Hua YQ, et al. The mitochondrial genomes of Culex tritaeniorhynchus and Culex pipiens pallens (Diptera: Culicidae) and comparison analysis with two other Culex species. Parasites Vectors. 2016;9:406.

9. Karthika P, Vadivalagan C, Thirumurugan D, Kumar RR, Murugan K, Canale A, et al. DNA barcoding of five Japanese encephalitis mosquito vectors (Culex fuscocephala, Culex gelidus, Culex tritaeniorhynchus, Culex pseudovishnui and Culex vishnui). Acta Trop. 2018;183:84-91.

10. Wilkerson RC, Linton YM, Strickman D. Mosquitoes of the world. Baltimore: John Hopkins University Press; 2021.

11. Marks EN. Recent taxonomic studies of Culex annulirostris and allied species and their possible significance for arbovirus research. In: George TD, Kay BH, editors. Arbovirus research in Australia, Proceedings 3rd Symposium 15-17 February 1982. Brisbane: CSIRO Division of Animal Health and Queensland Institute of Medical Research; 1982. p. 146-51.

12. Hemmerter S, Šlapeta J, van den Hurk AF, Cooper RD, Whelan PI, Russell $\mathrm{RC}$, et al. A curious coincidence: mosquito biodiversity and the limits of the Japanese encephalitis virus in Australasia. BMC Evol Biol. 2007;7:100.

13. Hemmerter S, Šlapeta J, Beebe NW. Resolving genetic diversity in Australasian Culex mosquitoes: incongruence between the mitochondrial cytochrome c oxidase I and nuclear acetylcholine esterase 2. Mol Phylogenet Evol. 2009;50:317-25. 
14. Australian Faunal Directory. Australian Biological Resources Study, Australian Government Department of Agriculture, Water and Environment, Canberra. 2021. https://biodiversity.org.au/afd/taxa/CULICIDAE/statistics. Accessed 30 Jul 2021.

15. Lee DJ, Hicks MM, Debenham ML, Griffiths M, Marks EN, Bryan JH, et al. The Culicidae of the Australian region, vol. 12. Canberra: Australian Government Publishing Service; 1989.

16. Batovska J, Lynch SE, Cogan NOI, Darbro JM, Kho EA, Blacket MJ. Effective mosquito and arbovirus surveillance using metabarcoding. Mol Ecol Resour. 2018;18:32-40.

17. Rohe D, Fall RP. A miniature battery powered CO: baited light trap for mosquito borne encephalitis surveillance. Bull Soc Vector Ecol. 1979;4:24-27.

18. Hajibabaei M, Janzen DH, Burns JM, Hallwachs W, Hebert PDN. DNA barcodes distinguish species of tropical Lepidoptera. Proc Natl Acad Sci USA. 2006;103:968-71.

19. Kumar S, Stecher G, Li M, Knyaz C, Tamura K. MEGA X: Molecular Evolutionary Genetics Analysis across computing platforms. Mol Biol Evol. 2018;35:1547-9.

20. Vesgueiro FT, Demari-Silva B, Malafronte RdS, Sallum MAM, Marrelli MT. Intragenomic variation in the second internal transcribed spacer of the ribosomal DNA of species of the genera Culex and Lutzia (Diptera: Culicidae). Mem Inst Oswaldo Cruz. 2011;106:1-8.

21. Chan A, Chiang LP, Hapuarachchi HC, Tan CH, Pang SC, Lee R, et al. DNA barcoding: complementing morphological identification of mosquito species in Singapore. Parasites Vectors. 2014;7:569.

22. Minh BQ, Schmidt HA, Chernomor O, Schrempf D, Woodhams MD, von Haeseler A, et al. IQ-TREE 2: new models and efficient methods for phylogenetic inference in the genomic era. Mol Biol Evol. 2020;37:1530-4.

23. Hoang DT, Chernomor O, von Haeseler A, Minh BQ, Vinh LS. UFBoot2: improving the ultrafast bootstrap approximation. Mol Biol Evol. 2018;35:518-22

24. Chernomor $\mathrm{O}$, von Haeseler $\mathrm{A}$, Minh $\mathrm{BQ}$. Terrace aware data structure for phylogenomic inference from supermatrices. Syst Biol. 2016;65:997-1008

25. Letunic I, Bork P. Interactive Tree of Life (iTOL): an online tool for phylogenetic tree display and annotation. Bioinformatics. 2006;23:127-8.

26. Zhang Z, Schwartz S, Wagner L, Miller W. A greedy algorithm for aligning DNA sequences. J Comput Biol. 2000;7:203-14.

27. Harbach RE, Knight KL. Taxonomists' glossary of mosquito anatomy. Marlton: Plexus Publishing Inc.; 1980.

28. Harbach RE, Knight KL. Corrections and additions to taxonomist's glossary of mosquito anatomy. Mosq Syst. 1981;13:201-17.

29. Asahina S. Transoceanic flight of mosquitoes on the Northwest Pacific. Japan J Med Sci Biol. 1970;23:255-8.

30. Nie WZ, Li JC, Li DX, Wang RJ, Gratz N. Mosquitoes found abroad ships arriving at Qinhuangdao Port, PR China. Med Entomol Zool. 2004:55:333-5.

31. Russell RC. A review of the status and significance of the species within the Culex pipiens group in Australia. J Am Mosq Control Assoc. 2012;28:24-7.

32. Clinton KJ, O'Gower AK. Mosquito survey. Darwin. Sydney: School of Public Health and Tropical Medicine, University of Sydney; 1950; pp. 1-18 (unpublished report).

33. Hodgkin EP, Britten EJ. A survey of the mosquito fauna of tropical Western Australia. R Comm Pub Health WA. 1955;1953:97-107.

34. Lee DJ. An atlas of the mosquito larvae of the Australasian Region: tribes Megarhinini and Culicini. Melbourne: Australian Military Forces; 1944.
35. Colless DH. Notes on the culicine mosquitoes of Singapore. Ann Trop Med Parasitol. 1957;51:87-101.

36. Whelan P, Hayes G, Carter J, Wilson A, Haigh B. Detection of the exotic mosquito Culex gelidus in the Northern Territory. Commun Dis Intell. 2000;24:74-5.

37. Muller MJ, Montgomery BL, Ingram A, Ritchie SA. First records of Culex gelidus from Australia. J Am Mosq Control Assoc. 2001;17:79-80.

38. Johnson PH, Hall-Mendelin S, Whelan PI, Frances SP, Jansen CC, Mackenzie DO, et al. Vector competence of Australian Culex gelidus Theobald (Diptera: Culicidae) for endemic and exotic arboviruses. Aust J Entomol, 2009;48:234-40.

39. Pearce JC, Learoyd TP, Langendorf BJ, Logan JG. Japanese encephalitis: the vectors, ecology and potential for expansion. J Travel Med. 2018;25:S16-26.

40. Kay B, Russell R. Mosquito eradication. The story of killing Campto. Collingwood: CSIRO Publishing; 2013.

41. Whelan P, Kurucz N, Pettit WJ, Krause V. Elimination of Aedes aegypti in northern Australia, 2004-2006. J Vector Ecol. 2020:45:118-26.

42. Tsuda S, Kim KS. Prediapause migration and overwintering of Culex tritaeniorhynchus (Diptera: Culicidae) observed in a park in urban Tokyo during 2007 to 2009. Med Entomol Zool. 2010;61:69-78.

43. Tsuda S, Hayashi T. Results of mosquito surveillance using dry-ice traps from 2003 to 2013 at the National Institute of Infectious Diseases, Tokyo, Japan. Med Entomol Zool. 2014;65:131-7.

44. Justi SA, Soghigian J, Pecor DB, Caicedo-Quiroga L, Rutvisuttinunt W, Li T, Stevens L, Dorn PL, et al. From e-voucher to genomic data: Preserving archive specimens as demonstrated with medically important mosquitoes (Diptera: Culicidae) and kissing bugs (Hemiptera: Reduviidae). PLoS ONE. 2021;16:e0247068.

45. Hone J. How many feral pigs in Australia? An update Aust J Zool. 2019;67:215-20.

46. Hone J. How many feral pigs in Australia? Aust Wildl Res. 1990;17:571-2.

47. Mackenzie JS, Johansen CA, Ritchie SA, van den Hurk AF, Hall RA. The emergence and spread of Japanese encephalitis virus in Australasia. Curr Top Microbiol Immunol. 2002;267:49-53.

48. van Den Hurk AF, Montgomery BL, Northill JA, Smith IL, Zborowski P, Ritchie SA, et al. Short report: the first isolation of Japanese encephalitis virus from mosquitoes collected from mainland Australia. Am J Trop Med Hyg. 2006;75:21-5.

49. van Den Hurk AF, Smith CS, Field HF, Smith IL, Northill JA, Taylor CT, et al. Transmission of Japanese Encephalitis Virus from the Black Flying Fox, Pteropus alecto, to Culex annulirostris mosquitoes, despite the absence of detectable viremia. Am J Trop Med Hyg. 2009;81:457-62.

50. Hanna JN, Ritchie SA, Phillips DA, Lee JM, Hills SL, van den Hurk AF, et al. Japanese encephalitis in north Queensland, Australia, 1998. MJA. 1999;170:533-6.

\section{Publisher's Note}

Springer Nature remains neutral with regard to jurisdictional claims in published maps and institutional affiliations. 